\title{
A Traditional Turkish Palate Taste: Cağ Kebab
}

\author{
Abdurrahman Kara \\ Faculty of Agriculture, Dicle University, Diyarbakır, Turkey \\ Email: abdurrahman.kara@dicle.edu.tr
}

How to cite this paper: Kara, A. (2017) A Traditional Turkish Palate Taste: Cağ Kebab. Open Access Library Journal, 4: e4120. https://doi.org/10.4236/oalib.1104120

Received: November 5, 2017

Accepted: December 12, 2017

Published: December 15, 2017

Copyright $\odot 2017$ by author and Open Access Library Inc.

This work is licensed under the Creative Commons Attribution International License (CC BY 4.0).

http://creativecommons.org/licenses/by/4.0/

\begin{abstract}
Cağ kebab is a sort of kebab similar to döner kebab that has traditionally been known and eaten in villages and city centres of Tortum, Uzundere, Oltu, Olur and Şenkaya districts of Erzurum province along with Yusufeli district of Artvin for centuries. Like döner kebab, skewered meat on a big skewer is roasted by turning around its long axis. However, what makes it different from döner is that the skewer of meat is not placed vertically, but is roasted horizontally in front of a wood fire or, preferably, embers of wood. Of course, the cooking technique is not the only difference that makes it unique. Perhaps the most important thing is the meat in this kebab which should be mutton or goat meat, especially from the leg and arms. The meat is prepared and left to rest for at least 12 to 24 hours before roasting. As this kebab is cooked by turning around its long axis in front of wood embers, roasted surface meat is cut in pieces after skewering on small skewers and then served on lavash bread with tomato, round chopped onion, and roasted green pepper. Cağ kebab takes its name from the small skewers, called "cağ", although they may also be called "bico". The difference in nomenclature is due to the material from which the skewer is made. If the skewer is made of iron, it is called "că̆", if it is made of wood, then it is called "bico". However, this traditional palate taste is more commonly known as cağ kebab and dealt with in detail in this paper to introduce and make it known to a wider mass of people.
\end{abstract}

\section{Subject Areas}

Food Science \& Technology

\section{Keywords}

Culinary Tourism, Regional Development, Cağ Kebab, Lavash Bread, Kadayıf Dolmasi, Erzurum, Turkey

\section{Introduction}

Having an important place in Turkish cuisine cağ kebab has traditionally been 
known and eaten in villages and city centres of Tortum, Uzundere, Oltu, Olur and Şenkaya districts of Erzurum province along with Yusufeli district of Artvin for centuries [1]. Based on the reports of Ottoman travellers, especially EvliyaÇelebi ${ }^{1}$, it has been narrated that this kebab is the ancestor of Döner kebab and originated to Kipchak Turks [2] [3]. It has been the most important food served in wedding ceremonies, entertainments, private and friend meetings in the given region for more than 300 years. However, there has been contradictory information on when this kebab was commercialized the first time. According to Oltu Chambers of Commerce which has a geographical indication for this kebab with the name of Oltu Cağ Kebabı, there had been an increase in the number of cağ kebab restaurants in 1960s after it had been served the first time in a barrack-like building by a man with livelihood challenges [2].

On the other hand, Kemal Koç, one of the leading cağ kebab master chefs serving in Erzurum central district, stated that this kebab dated back to Ottoman period and known as bico at that times and claimed that he had commercialized it the first time by introducing it to restaurant cuisine in 1982 with the name of "Tortum Kebabı Cağlı". He also claimed that he had the trademark of this kebab with the title of "Tortum Meşhur Koç Cağ Kebabı (Tortum Famous Koç Cağ Kebab)" by registering it in 2000 [4]. Similar information regarding the history of Cağ Kebab was also reported by Şakir Aktaş, one of the leading cağ kebab master chefs serving in Erzurum. As Kemal Koç did, he also claimed that he had the registered trademark of Tortum Cağ Kebab [5]. Both Cağ Kebab Master Chefs stated that this kebab was given the name of "cağ kebab" due to that the skewers were known or called as cağ which were used in serving of this kebab. They warned that this special kebab had been mispronounced as "çağ kebab" in some places [2] [4] [5].

\section{Characteristics of the Meat to Be Used and Its Preparation}

Cooking technique is not the only difference which makes this kebab unique. Maybe the most important crux is hidden in the characteristics of the meat used in preparation of this kebab [7]. It is necessary that the meat used to make cağ kebab be obtained from the hogget naturally raised in high plateaus of Erzurum and Kars provinces. Although all meats to be obtained from the carcass (excluding the tail ${ }^{2}$ ) can be used, the meats from hind and forelegs should be preferred in preparation of cağ kebab. Fat/lean ratio should be $1 / 4$ or at most $1 / 3$. If the mutton is fattier, then it can be balanced with beef. For the most desired taste

\footnotetext{
${ }^{1}$ In his famous book of travels "Seyahatname", the Ottoman traveller Evliya Çelebi, one of the prominent travellers of the $17^{\text {th }}$ century, gave important information on political, social and cultural lives of Nogai Tatars living in the geography mentioned by himself as Kipchak Steppe (Dasht-i Kipchak), which covers the north of Black sea and Caucasus, especially the area laying between Dniester and Irtysh rivers. In this information was mentioned a kebab made of mutton skewered in a big skewer and roasted with wooden cart wheel used as woodfire [3] [9] [10]. This information is quite similar to that of cağ kebab. Moreover, locally denominating the well roasted cağ kebab as Tatari [8] [11] strengthens this information.

${ }^{2}$ Tail fat is not used since it causes undesirable odour.
} 
and flavour meat of 100 percent beef meat is not suggested. In case of using beef to balance fat/lean ratio the meats should necessarily be obtained from hind legs or forelegs of young cattle. On the other hand, although it is possible to use goat meat for this kebab, in that case it is reported that pasture based fattened male or females can only be used from July to the breeding season since there will be an undesired odour in goat meat in breeding season. Even though some chefs suggest Kivirclk sheep ${ }^{3}$ for cağ kebab preparation [1], all sheep breeds including fatty-tailed ones can be used for this purpose [8].

Since meat cutting and seasoning are other points requiring mastery and skill, cağ kebab chefs should pay attention to every step from slaughtering to seasoning the meats. Meat cuts should not thin or thick because they will shrink or not be delicious when thin or thick meat cuts are used respectively [1].

In seasoning the meat cuts, only salt, onion and black pepper are used and the use of anything else such as thyme or basil is not suggested [1] [6] [13]. However, it is noted that great attention should be paid to the onion to be used since every type of this vegetable is not preferred in cağ kebab. Pungent onion varieties are not preferred and white coloured varieties ranging in flavour from sweet to mild must be used. Moreover, it is emphasized on that onion taste should not be preponderant and felt in this kebab [1].

Meat pieces to be skewered are prepared through cutting two $\mathrm{cm}$ thick meat leaves trimmed and cleaned from nerves, veins, membranes and excess fats. Although there is no a certain measure, it is suggested that leaf meat pieces to be prepared should be in size proportional to the length and diameter of the skewered skewer. For example, if the skewered diameter of the skewer is $30 \mathrm{~cm}$, then, its length should be $60 \mathrm{~cm}$ [13].

Prepared meat leaves are kneaded with salt, black pepper and onions chopped in cooking and left to rest for 12 to 24 hours in a refrigerator or a cool place [4] [5] [8] [11] [13]. It is also possible to coincide information in some recipes suggesting that meat leaves should be marinated with yoghurt in addition to salt, black pepper and chopped onions. However, this is only possible in case of using beef to balance fat/lean ratio to soften the beef and that the beef should be marinated separately without mixing it with mutton [8]. Again, in some recipes, it is reported that meat leaves salted and rested for 24 hours are made ready to roast with the special pasty mix prepared through kneading the finely chopped onion with black pepper [13]. Seasoned and rested meat leaves are skewered to a big skewer one after another by pressing each time [8] [11]. If beef is used to balance fat/lean ratio, beef and mutton should be skewered in a mixed order of one beef leaf and then one mutton leaf or vice versa [8] (Figure 1).

\footnotetext{
${ }^{3}$ Kıvırcık is one of the indigenous sheep breeds of Turkey. It is a long lean tailed and multipurpose sheep mainly raised in North Aegean and all over the Marmara regions of Turkey. There have been milk-first and mutton-first types of this breed. Herd instinct and ability to walk long distances in rough terrain is well developed. Due to abstinent nature and robust body structure it is high adaptability and hardy to unfavourable environmental conditions, especially well adapted to high altitude, cold and damp areas. Carcass and milk yield is quite good. Dispersed fat among the muscles and muscular fibres, which is called marbling, gives the meat flavour and tenderness [12].
} 

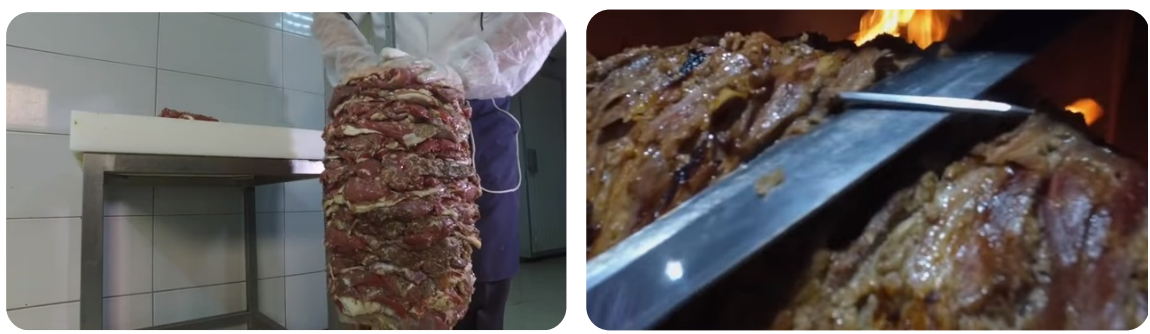

Figure 1. Skewering and roasting the cağ kebab [5].

Upon completion of skewering the meat leaves, the big skewer is fastened with a pin to prevent them from loosening. It is important that the big skewer should be made of iron or preferably chrome, and the part of skewering should be $2 \mathrm{~cm}$ $\times 2 \mathrm{~cm}$ in cross section [13].

\section{Roasting the Meat}

As in döner kebab, the skewered meat is roasted by rotating the skewer in front of fire until the meat colour changes from red to brown. Yet, what makes it different from döner kebab is that the skewer of meat is not placed vertically, but is roasted horizontally at a height of $10-15 \mathrm{~cm}$ from the base of fireplace and in front of a wood fire or, preferably, embers of wood from the side.

For own unique flavour of the cağ kebab, it is important that especially fruit or oak wood should be preferred for firewood [2] [4] [5] [8] [11] [13] [14] and stone or brick fireplaces should be used [13]. Fireplace is fired 15 - 20 minutes beforehand to obtain perfect heat and sufficient ember prior to roasting. Later, the fire is gradually fed with firewood [8]. As the one side of the skewered meat roasted, the skewer is rotated to cook the other sides. Changing of the colour of meat from red to brown indicates that cağ kebab is ready to be served (Figure 1) [2] [8] [11] [13].

\section{Serving and Catering}

This kebab is traditionally served with pointed small skewers which are called "cağ". They should be made of iron or preferably chrome with wooden handle and the part on which meat is skewered should be $20 \mathrm{~cm}$ in length and $2 \mathrm{~mm} \times 3$ $\mathrm{mm}$ in cross section. As stated earlier this special kebab takes its name from these small skewers. Nevertheless, upon request it can be served in dishes as is the case in döner kebab. The amount of one portion kebab varies according to the way of serving and, in general, it is about $80 \mathrm{~g}$ or $100 \mathrm{~g}$ when served in cağ or dish respectively [2] [13] [15].

As was in the past, it is still possible to see the use of thin wooden skewers ${ }^{4}$

${ }^{4}$ Thin branches of the bushes in the natural vegetation of the region, especially divergent maple (Acer divergens), an endemic species in Çoruh Basin, and bladder senna (Colutea armena) [16], is used in making bico. These branches have a very hard and robust structure when get dried. In addition to those of divergent maple and bladder senna, branches of other bush species, for example, Eurasian smoke tree or smoke tree (Cotinus coggygria) which is very common in the area and locally called as "Garbeş Çalısı" are also used in making bico (Figure 2). 


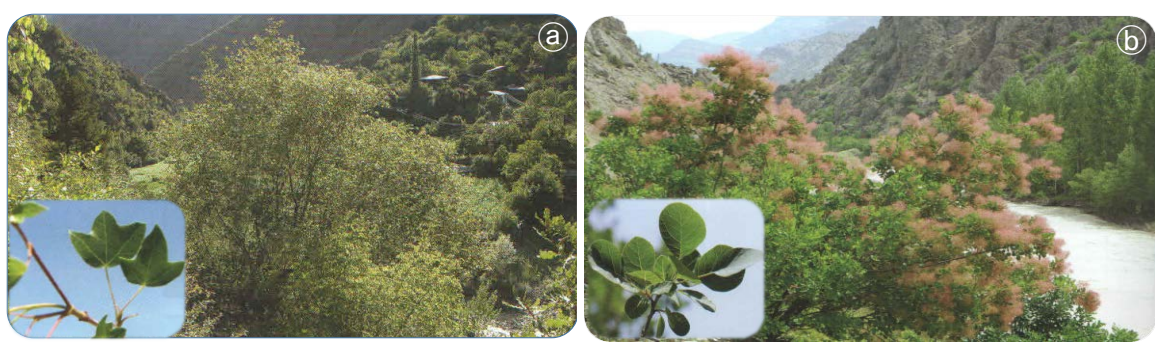

Figure 2. (a) Divergent maple (Acer divergens), (b) Eurasian smoke tree (Cotinus caggygria) [16].

called "bico" in Tortum and Yusufeli districts [8]. In serving the cağ kebab, că̆ or bico is inserted into the roasted surface meat at the big skewer and roasted surface meat is cut out from the main block with a big kebab knife allowing the meat pieces skewered in the small skewers (cağ or bico) to be $4-7 \mathrm{~mm}$ in thickness. Cağs or bicos are served as partially fatty and relatively less roasted, pink coloured in one side. Yet, upon request relatively less roasted pink side of the cağ or bico can be roasted a little bit more on the grill at the side of fireplace [1] [8] [11] [13]. Well roasted kebab is locally called as Tatari. Roasted and skewered kebab in cağs or bicos is dressed up with round finely chopped onion, tomatoes and grilled green pepper, and served with indigenous lavash ${ }^{5}$ or tandoor bread and season salad along with the options of buttermilk and turnip juice (Figure 3a) [1] [4] [5] [6] [8] [11] [13].

After cağ kebab serving, catering is completed with either of the two traditional desserts of Erzurum province, Kadayıf dolmasi ${ }^{6}$ and fig $\operatorname{dessert}^{7}$ [1] [4] [5] [8] [11].

\section{Where to Eat}

Today, the number of cağ kebab restaurants increase in many cities especially in Bursa, Ankara, İstanbul and Antalya day by day and this traditional palate taste is introduced to the acclaim of people. However, in order to experience the real taste and flavour, and to feel the unique deliciousness left on the palate, cağ kebab should be eaten in its original and natural geography where it was born and has been roasted and consumed for centuries. In this geography, which covers above mentioned districts of Erzurum and Artvin provinces, this kebab is prepared and served with a great mastery and skill especially in almost all restaurants,

\footnotetext{
${ }^{5}$ Lavaş or lavash bread is another traditional food and generally baked and consumed in a wider geography covering Turkey, Iran, Azerbaijan, Kirgizstan, Kazakhstan and Armenia. It is baked in tandoors and only flour, water and salt are used without any other ingredients, including yeast, in making this traditional bread (Figure 3b). It has a thin and circled shape, but its thickness varies place to place. The ever-thinnest (about $1 \mathrm{~mm}$ ) lavaş bread is baked in Erzurum. It is especially used for making dürüm (rolled-up sandwich) by wrapping cheese, kebab or any kind of food.

${ }^{6} \mathrm{It}$ is a kind of dessert from the cuisine of Erzurum Province, made of finely shredded dough (kadayif) and ground walnut. Ground walnut is wrapped with kadaylf in a size of $8-10 \mathrm{~cm}$ in length and $2-3 \mathrm{~cm}$ in diameter. Kadaylf wraps are dipped in beaten egg, fried in boiling vegetable oil, soaked in cooled syrup and then served (Figure 3c).

${ }^{7}$ It is prepared with sugar and already milk soaked figs filled with coarsely ground walnut and cinnamon powder.
} 


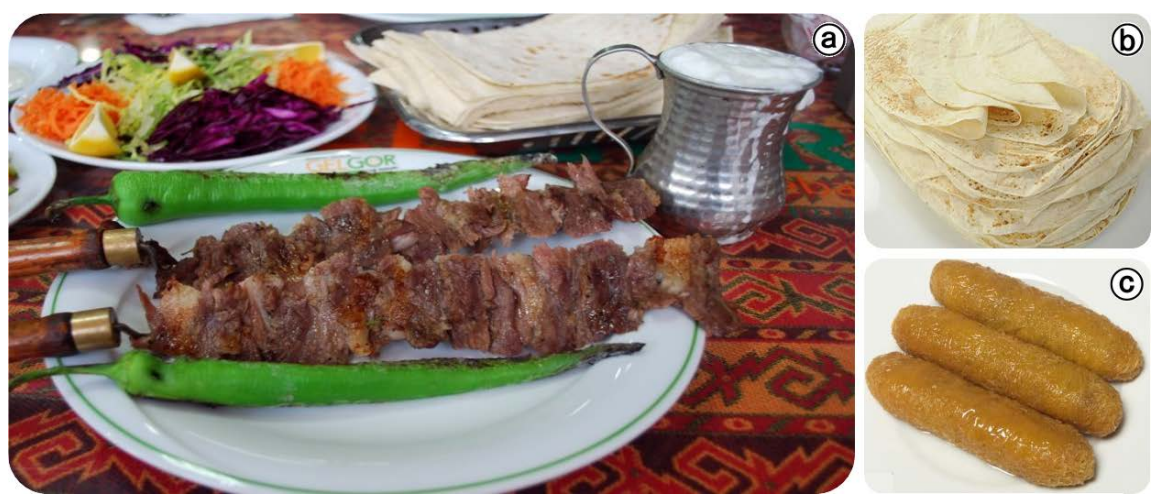

Figure 3. (a) The way of serving the cağ kebab; (b) Lavash bread; (c) Kadayıf dolması [5].

tea gardens or especially on road restaurants which serve merely cağ kebab.

Nevertheless, cağ kebab restaurants of Aksukapı, Pehlivanlı and Engüzekkapı on the Tortum-Uzundere road are the well-known places. Also, Koç Kebap and Gel-Gör Restaurant are particularly the most preferred restaurants in Erzurum city centre.

\section{Conclusions}

Lin et al. [17] emphasized on that foods are related to social, cultural and natural characteristics of a particular geography and that they are a symbol and an emblem of a region, and a sign of culture. Since tourists in their visiting sites generally prefer the foods and meals [18], traditional and local foods have a great tourism potential. Insomuch that gastronomy or culinary tourism represents a new tourism market and becomes more and more popular. This tourism branch constitutes especially the main or at least additional activities of the tourists in the enterprises in a given destination. Even in some circumstances, the main motivating factor of the tourism trips has been the desire of knowing and experiencing this unique regional food culture. Along with other local, cultural and social values, as a traditional food, cağ kebab has the potential of enhancing and strengthening the authenticity, hospitality and economy of Erzurum province [17] [19] [20].

Unfortunately, today, there has been a fervent and needless debate between Oltu and Tortum districts of Erzurum province regarding the origin of this kebab. Whereas, as in the adage of "water flows and finds its way", this kebab has been a trademark of Erzurum province over the years and henceforth, it has been known as "cağ kebab" regardless of its origin. For that reason, no matter how it is called, either "Oltu Cağ Kebabı” or "Tortum Cağ Kebabı”, this unique palate taste is an important cultural wealth component of Turkey and most likely will have a role in the regional development as long as it can be considered in the context of gastronomy or culinary tourism. To achieve this outlined goal, cağ kebab should be introduced to a wider range of people worldwide and should be served to the customers at a more competitive price. 


\section{References}

[1] Çakır, Ş. (2015) Erzurum and Cağ Kebab.

http://www.gonuldergisi.com/erzurum-ve-cag-kebabi-saban-cakir.html

[2] Anonymous (2015) The History of the Oltu Cağ Kebab. http://www.dadasogluoltucagkebap.com/cktarihi.html

[3] Yerasimos, M. (2014) Food Culture as Mentioned in Evliya Celebi's Book of Travels (Seyahatname): Comments and Systematic Index. Kitapyayınevi, İstanbul, 555.

[4] Koç, K. (2015) Koç Meşhur Tortum Cağ Kebab. http://www.koccagkebap.com/

[5] Aktaş, Ş. (2015) Gel-Gör Tortum Cağ Kebab. http://www.gelgorcagkebabi.com/

[6] Anonymous (2015) Cağ kebab. http://www.forumgercek.com/et-yemekleri/90053-cag-kebabi-erzurum-ve-artvin-y oresi.html

[7] Anonymous (2009) Geographical Sign Registration Certificate for OltuCağ Kebab. Turkish Patent and Trademark Office, Ankara.

[8] Güzel, H. (2015) Personal Communication. Uzundere Cağ Kebap Salonu, Uzundere.

[9] Başer, A. (2011) The Nogais in the Seyahatname of EvliyaÇelebi. Journal of Turkish World Studies, 11, 117-128.

[10] Kahraman, S.A. (2011) Evliya Celebi's Book of Travels in Contemporary Turkish Language. The Second Book of Volume 7, YapıKrediYayınları, İstanbul.

[11] Koç, K. (2015) Personal Communication, Koç Cağ Kebap Salonu, Erzurum.

[12] TAGEM (2009) Introductory Catalog for the Farm Animals Genetical Resources of Turkey, General Directorate of Agricultural Research and Policies, Ankara.

[13] Anonymous (2015) Oltu Cağ Kebab with All Subtle Details. http://www.oltulular.com/cag_kebabi.asp

[14] Anonymous (2015) Cağ Kebab. http://www.ercag.com/cagkebap.html

[15] Anonymous (2008) Cağ kebabı Will Be a Registered Trademark. http://ekonomi.haber7.com/ekonomi/haber/312878-cag-kebabi-tescilli-marka-olacak

[16] Mamikoğlu, N.G. (2015) Trees and Bushes of Turkey. NTV Yayınları, İstanbul.

[17] Lin, Y., Pearson, T.E. and Cai, L.A. (2011) Food as a Form of Destination Identity: A Tourism Destination Brand Perspective. Tourism and Hospitality Research, 11, 30-48. https://doi.org/10.1057/thr.2010.22

[18] Yüncü, H. (2010) Gastronomy Tourism and Perşembe Plateau in Point of Sustainable Tourism. In: Şengel, S., Ed., The 10th Aybastı-Kabataş Congress. Local Values and Plateau Tourism, Detay Anatolia Akademik Yayıncılık, Ankara.

[19] du Rand, G.E., Heath, E. and Alberts, N. (2003) The Role of Local and Regional Food in Destination Marketing: A South African Situation Analysis. Journal of Travel and Tourism Marketing, 14, 37-112. https://doi.org/10.1300/J073v14n03_06

[20] Everett, S. and Aitchison, C. (2008) The Role of Food Tourism in Sustaining Regional Identity: A Case Study of Cornwall, South West England. Journal of Sustainable Tourism, 16, 150-167. https://doi.org/10.2167/jost696.0 